Journal of Contemporary Research in Social Sciences

ISSN : 2641-0249

Vol. 3, No. 3, pp. 48-61.

2021

Publisher: Learning Gate

DOI: 10.33094/26410249.2021.33.48.61

(C) 2021 by the authors; licensee Learning Gate

\title{
Difficulties in Learning and Teaching Programming at Lower Secondary Level in Mauritius
}

\author{
Vinod Sharma Bhaugeerutty \\ Mauritius Examinations Syndicate, Mauritius. \\ Email:vsharma471@yahoo.co.uk
}

Received: 31 May 202 1; Revised: 2 June 2021; Accepted: 26 July 2021; Published: 23 August 2021

\begin{abstract}
The rapid evolution of technology around the world has created a rapid growth and efficient learning environments. In Mauritius, for example, the government is investing huge amount of money in the educational sector with initiation of programming at an early stage. The ideology behind this push is to strengthen the link between the younger generation and the technological growth that will continue to have an ever-increasing impact on their lives and to fuel the pace of innovation. One of the core themes of this area is that of computer programming, which has now become a mandatory subject in early years' education. As a result of this change, many challenges are being faced by educators and students; for example, educators require more training and students need appropriate tools that suit their level of learning. Therefore, this research aimed at exploring the difficulties in learning and teaching programming at lower secondary schools in Mauritius. Consequently, it can be interpreted from the research findings that an automated teaching and learning programming system that supports the right pedagogical aspects, example, assessment-driven learning with the inclusion of game-based learning, would make the learning process more successful and enjoyable for students in early years of education. Students with higher problem-solving abilities find programming easy and they can master programming with no or little difficulties regardless of the programming environment. On the contrary, students with lower problem-solving abilities find programming difficult to understand and are often unable to master it.
\end{abstract}

Keywords: ICT - Information and Communication Technology, NYCBE - Nine Year Continuous Basic Education, QAD Quality Assurance Division, PCK - Pedagogical Content Knowledge, Mauritius examination syndicate (MES), Information technology (IT), List processing (LIST).

\section{Introduction}

The theory of programming comprises of knowledge of any programming language, pseudocode, algorithm, flowchart and problem-solving skills. The regular method in programming is to initiate the basics and construct in programming so as to effectively channel the students towards developing programming skills. The curriculum related to programming usually stresses on developing problem solving and computational thinking skills. The code craft project was initiated to promote the learning of basic programming skills and data structures. To have an effective concepts and educational strategies for the usage of programming it is vital to review the various studies carried out in this domain.

This report emphasizes on the teaching and learning of programming at lower secondary school (meaning grade 7 to 9) in Mauritius as no such studies have been carried out. According to a Survey of ICT and Education in Africa: Mauritius Country Report (2007) Information and Communication Technology (ICT) has been introduced since 1991 in secondary schools. It was not immune to problems and it has a weak position in the secondary education curriculum where it was not considered as a main 
subject until the national assessment of education was implemented. Another setback of teaching ICT was the lack of Computer Science educators as they were mainly from the information systems or Information Technology background. The computer educators have tried out several strategies to tackle the pitfalls of teaching and learning programming however the students did not perform satisfactorily.

\section{Mauritius Education System}

The Mauritian Education System has structured its pathway to easily monitor the performance of the students in an incremental manner. The progression of education is initiated from the age of 3 to 5 as pre-primary to tertiary after 18 years by going through primary and secondary schools.

The implementation of the NYCBE (Nine Year Continuous Basic Education) in 2018 has transformed the Mauritian education system. The educational reform aims at equipping the students with knowledge and skills in achieving the 2030 ministry of education vision. The primary level students are assessed after 6 years to obtain their level one certification and secure admission to secondary schools.

During the secondary level schooling the students will be examined after their grade 9 to obtain their level 2 certification. After the assessment the students will secure admission in academies, regional or vocational schools. Having completed their grade 13 students are entitled for tertiary education.

\subsection{Computer Education in Mauritius}

According to the Ministry of Education Arts and Culture (1991) an entire chapter was dedicated to computer education in schools. The plan stated that implementation of computer usage in schools occurred during 1982-83 and in 1986 the Ministry of Education initiated Computer Literacy which consisted of the computer operations, programming and some common application software like Microsoft Word, Excel, PowerPoint as a pilot study in 10 secondary schools around the island in Form 3. The implementation of computer education has not been implemented successfully because of lack of resources and practical sessions. Another pitfall was the lack of trained educators and a solution to this problem was to provide Bachelor of Education course in computer education by the Mauritius Institute of Education. The ICT subject was being assessed at school level at that time.

According to the Ministry of Education plan 2012, the Mauritius Examination Syndicate (MES) is responsible to carry out the National Assessment at Form 3 (today known as Grade 9). The computer education (also known as Information Communication Technology (ICT)) in Mauritius exhibits some fragile points such that the curriculum does not elaborate the skills and competencies which students are supposed to acquire in order to guarantee its standard as it was an optional subject at School Certificate level. Report from the Quality Assurance Division (QAD) of the Ministry of Education clearly show that there has been a decrease in the percentage pass from the last decade. As regard to the item analysis for the ICT assessment, it is clear that the decline is mainly due to problem solving and programming concepts.

\subsubsection{Programming Education}

Programming is one of the nine content areas that are being assessed in ICT at lower secondary in Mauritius as the curriculum has been design to allow the learners developed their ICT skills and competencies to face the challenging technological world. It helps to demonstrate problem solving and logical reasoning skills through computational thinking.

Programming involves a number of stages in coding, debugging and maintaining the source code of a program (Wikipedia, 2020). Mawby, Kurland, Pea, and Clement (2009) defined programming as an expertise which is difficult to study, however, if effective teaching strategies are employed, it can help students to master the concepts easily. This report will emphasize on investigating the challenges associated with teaching programming. The aim is to support the educator as well as the students with an appropriate method that can support students to amusingly cram and sustain educators in the 
learning process by monitoring students' performance (Stephenson, Gal-Ezer, Haberman, \& Verno, 2015).

\section{Aim of the Study}

Computer programming has been a compulsory content in the ICT curriculum since the implementation of the national assessment in Mauritius. This initiation of programming at grade 7 has brought about many pitfalls such as educators requiring appropriate textbooks, hardware with appropriate programs and programming skills to facilitate the initiation of programming. However, the introduction of programming such as scratch is an important technological development in problem solving and critical thinking in ICT.

This report will provide solutions to the different pitfalls and aims at:

- Identifying the drawbacks related to the teaching and learning of programming.

- Integration of computer game learning such as scratch thereby engaging students in learning programming

\section{Pedagogical content knowledge of programming}

Pedagogical Content Knowledge (PCK), is a theory defined by Koehler and Mishra (2009) whose techniques demonstrate and express the content area of a subject and thus making it understandable. The PCK incorporates an appreciation of the difficulty level of the different learning outcomes (Shulman, 2006). From various studies it can be concluded that there are various types of learning styles to satisfy the needs of the learners (Rayner, 2015). The answers of the main questions of the PCK for programming are shown in Figure 1.

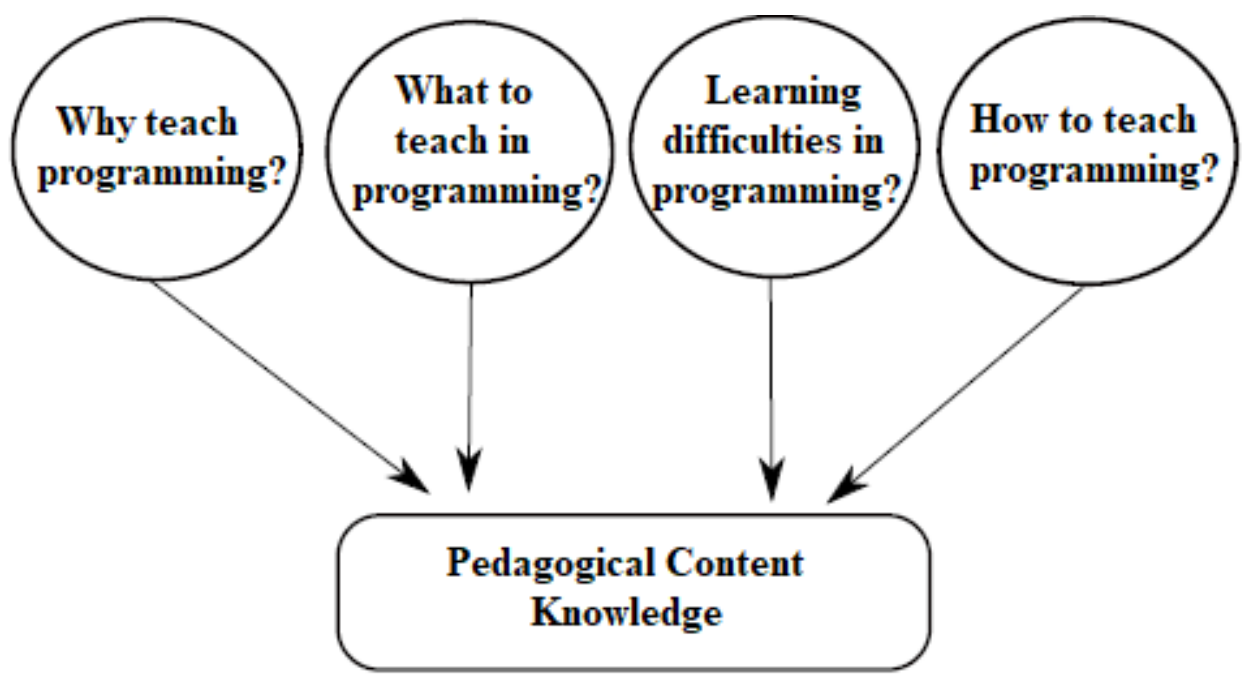

Figure-1.

An adaptation of Grossman's reformulation of PCK.

\subsubsection{Why Teach Programming?}

Why do we need to teach programming at lower secondary level? This question should have been better formulated as "why should the students learn programming?" and the outcome of this question will be of interest from an educator's point of view. This will therefore motivate educators in promoting ICT and help students to better engage in computer or Information Technology (IT) related courses at tertiary level. However, this is not the goal of this paper. 
Papert (2006) highlighted the importance of studying programming as it helps students to better develop their problem-solving and critical thinking skills. Students have to undergo a number of stages in achieving the solution for a particular problem by adopting different programming syntax.

\subsubsection{What Should Be Taught?}

The answer to this question will help us formulate the key concepts of programming which is about finding solutions to problems. At lower secondary level programming key concepts involve flowcharts and algorithms. These are applied in problems where learners have to translate their programming skills into coding solutions to problems. Different programming tools have been adopted as learning strategies to facilitate the teaching and learning of programming (Resnick et al., 2009). These are shown in the Table 1:

Table-1.

Current Programming Teaching Tools used in the ICT curriculum.

\begin{tabular}{|c|c|c|c|}
\hline Language & Description & Date & Shortcoming \\
\hline Logo & $\begin{array}{l}\text { It is an educational tool that was } \\
\text { used to teach learners programming } \\
\text { concepts related to Lisp. }\end{array}$ & 1967 & \multirow{2}{*}{$\begin{array}{l}\text { The idea of assessment for learning is } \\
\text { missing from those tools. There is no } \\
\text { consideration of the learners pre- } \\
\text { knowledge of programming. Monitoring } \\
\text { the progress of learners is also missing } \\
\text { from these. Programming tools. }\end{array}$} \\
\hline Scratch & $\begin{array}{l}\text { It is a graphical tool that can be } \\
\text { used by pupils to make animated } \\
\text { stories, games and so on. }\end{array}$ & 2006 & \\
\hline
\end{tabular}

\subsubsection{What are the Learning Difficulties?}

Understanding and coding applications is usually thought to be tough and the chapters related to programming and algorithms have led to increase in student's dropout percentage. Soloway and Spohrer (2009) pointed that a student needs at least 10 years of programming experience to master it properly. Various researchers have conducted different studies on the differences between objectoriented and procedural languages where $\mathrm{C}++$ and Java are extensively used as educational languages. The answer for this question will help us identify the different drawbacks for learning programming and Govender (2006) identifies these difficulties:

1. Discover programming is useful and how beneficial it will be when studying programming.

2. Understanding the syntax of programming.

3. Understanding the concept of programming construct in term of sequence, selection and iteration.

4. Grasping the key concepts of algorithm, flowchart and pseudocode.

\subsubsection{How to Teach Programming?}

The answer to this question will serve to recognize the different strategies used to initiate programming, deal with complexities involved in teaching and eventually motivating students to enjoy programming. Hromkovi ${ }^{`} \mathrm{c}$ (2006) pointed out that programming can be seen as a communication skill in problem solving by setting instructions. It is a method to initiate students in writing simple syntax in any programming language. Thus, writing instructions helps in problem solving which is directly related to algorithms.

\section{Taxonomy of Education}

According to Forehand (2010) Bloom's taxonomy attributes help educators in arranging their educational goals and teaching strategies. In addition, Bloom has identified cognitive, affective and psychomotor as the educational goals (Krathwohl, 2012). They updated the six levels in the taxonomy based on feedback from teaching practitioners and their interactions with students, from lowest to 
highest, as Remembering, Understanding, Applying, Analysing, Evaluating and Creating as shown in Table 2.

Table-2.

Bloom's categories and programming directives.

\begin{tabular}{l|l}
\hline \multicolumn{1}{c|}{ Bloom's Categories } & \multicolumn{1}{c}{ Programming directives } \\
\hline Remember & Can the student remember the syntax of example an iteration? \\
\hline Understand & Can the student remember the operation of example an iteration? \\
\hline Apply & Can the student implement example iteration? \\
\hline Analyse & Can the student differentiate between iteration and sequencing? \\
\hline Evaluate & $\begin{array}{l}\text { Can the student decide whether it is better to use sequencing or iteration in the } \\
\text { given question? }\end{array}$ \\
\hline Create & Can the student design an application? \\
\hline
\end{tabular}

Thompson (2008) also developed Bloom's taxonomy, citing the difficulties in applying the levels of cognition to software engineering and programming; in their work, the categories were explained using examples specific to programming. Therefore, this taxonomy has been used in the teaching of programming to allow learners in recalling the information from memory that are needed for writing a code and understanding the syntax of a structure used in the program. For example, students at this level should be asked to name the different types of iteration. In short, learners at this level are expected to recall from memory what they have learnt in the classroom.

\section{Learning Styles}

Rutherfoord and Rutherfoord (2008) outlined that learning styles are the desired methods of studying new concepts that will help in understanding and retaining contents. According to Stickel (2009) the different learning styles of the students has an impact on the teaching strategies of the educators as they have limited time devoted for the preparation of their lessons. As learning styles are dynamic, we will concentrate on the following Figure 2.

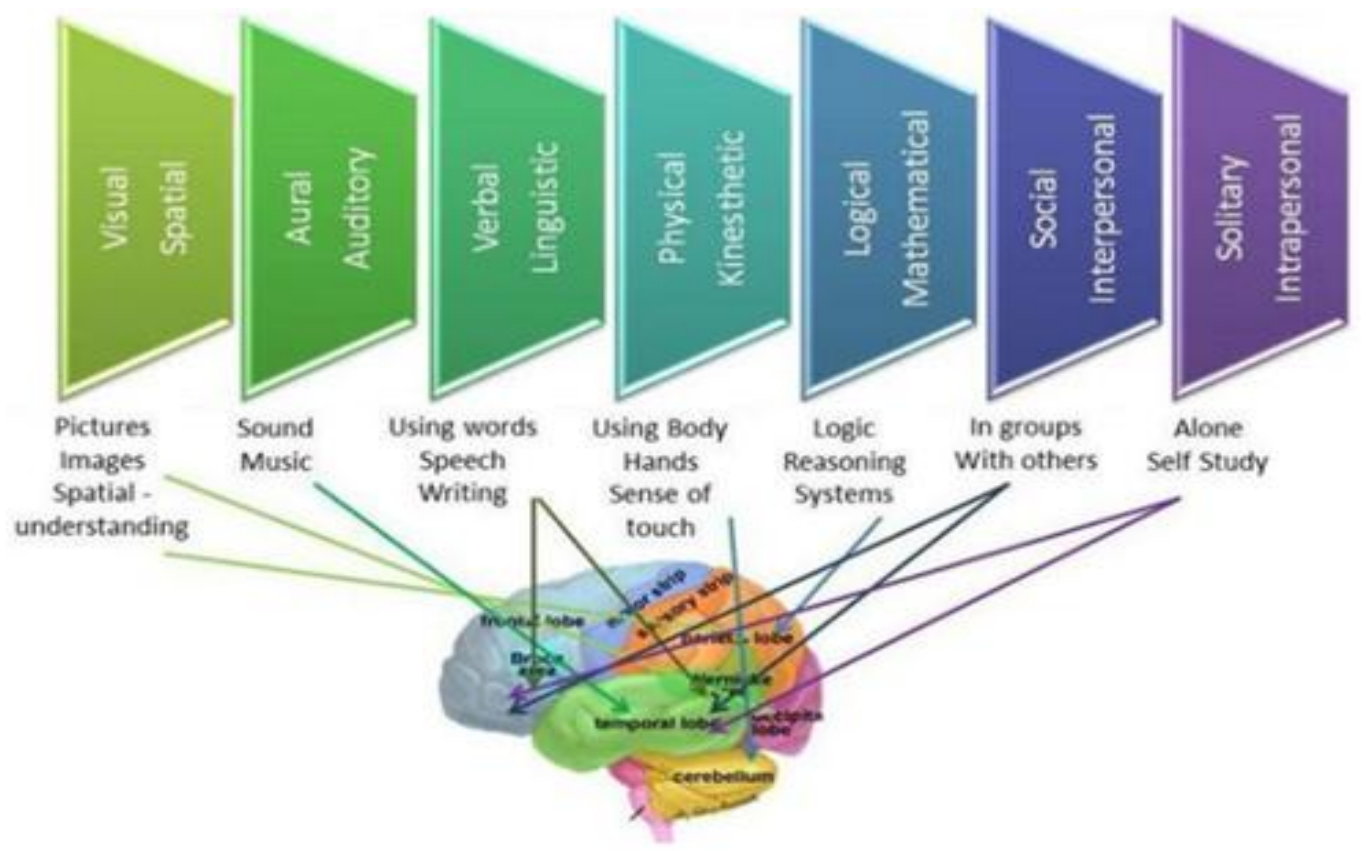

Figure-2.

Learning styles.

Journal of Contemporary Research in Social Sciences
ISSN : 264.1-0249
Vol. 3, No. 3, pp. $48-61,2021$
DOI: $10.33094 / 26410249.2021 .33 .48 .61$
C) 2021 by the authors; licensee Learning Gate


Learning to code has many layers from learning the actual programming languages to learning how to think like a programmer. Complicating the learning process is the fact that everyone learns differently. There is no one correct way for learners to learn. Some learners are evenly split between one, two, or maybe even three different learning styles as described below.

- Visual (spatial): Learner prefers the use of pictures, images, and spatial understanding.

- Aural (auditory-musical): Learner prefers to use sound and music.

- Verbal (linguistic): Learner prefers to use words, both in speech and writing.

- Physical (kinesthetic): Learner prefers using your body, hands, and sense of touch.

- Logical (mathematical): Learner prefers using logic, reasoning, and systems.

- Social (interpersonal): Learner prefers to learn in groups or with other people.

- Solitary (intrapersonal): Learner prefers to work alone and use self-study.

When teaching students programming, the use of visual, verbal and logical learning theory can be included by making the learning into a form of problem solving and letting them learn programming concepts through solving a problem. In the learning programming, students learnt concepts such as iteration by having to use their analytical skills to solve a problem. The concept of differentiation is critical and means that teachers provide instructional strategies that support the various learning styles of their students.

\section{Learning Programming through Scratch}

Teaching programming was initiated through gaming where learners had to be familiarized through instruction. According to Papert (2006) Logo programming was best suited for learning programming. Scratch programming through the code craft project in the Mauritian Educational System was implemented to develop the programming skills of students of Grade 7 . The use of colour coded blocks of code was adopted to overcome the different pitfalls that students had in learning programming, which eventually had helped students from typing mistakes and enjoyed programming.

For example, students were given a small project to check the password. They have drawn a flowchart and then code it through Scratch and Python.
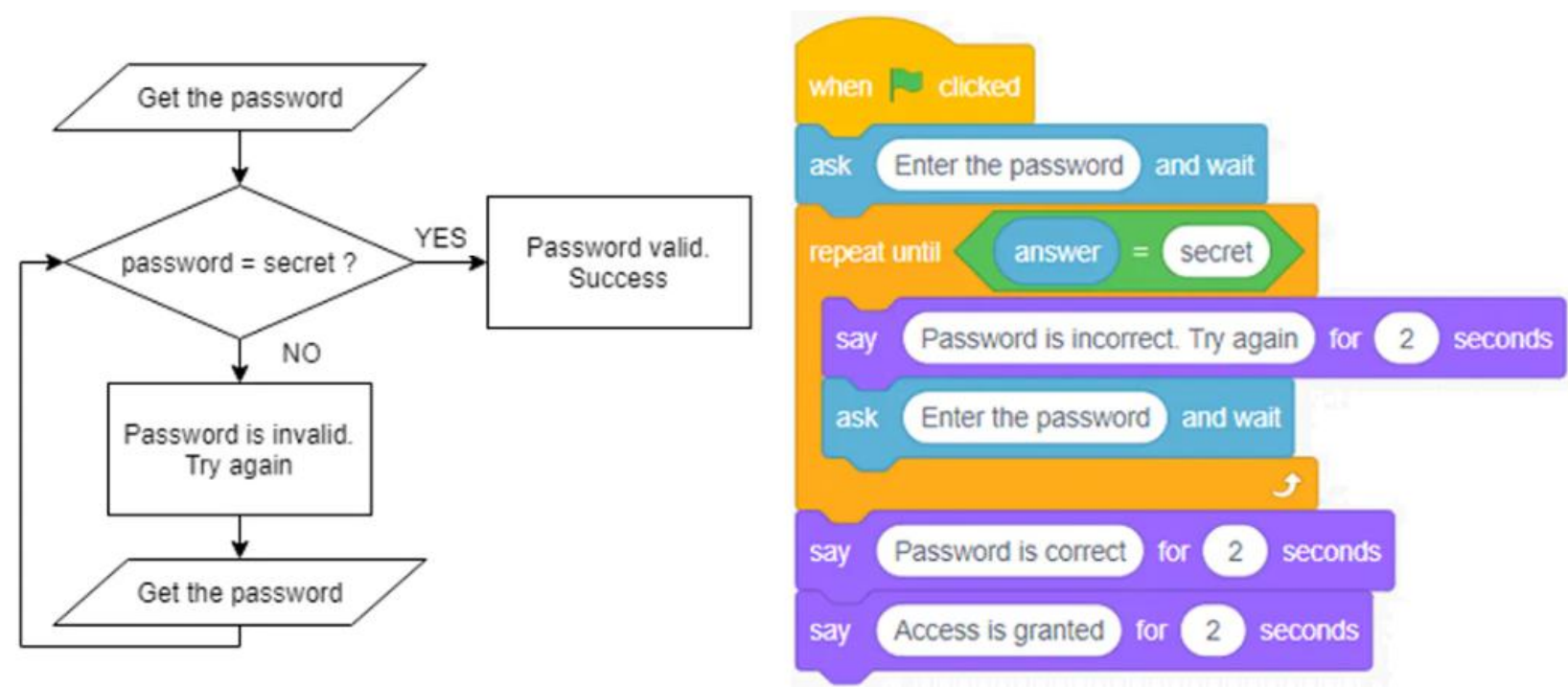

Figure-3.

Flowchart and Scratch block of code to check password.

Regarding the iteration-programming concept, students were introduced to the repeat block as a way to repetitively make scripts shorter. The block is going to check its Boolean condition and then 
accordingly; it will act (if it is YES, the blocks held inside it is going to run whereas, if it is NO, the code inside the block is going to be repeated until the password is correct) Figure 3.

According to Armoni, Meerbaum-Salant, and Ben-Ari (2015) higher order thinking is essential for students in problem solving and students with this competency can easily master the programming concepts and eventually motivates others to learn. On the other side, students with lower problemsolving skills have to struggle a lot to learn programming and they are sometimes demotivated and dropped ICT at higher secondary level. The lower problem-solving ability students usually perceived programming language as an obstacle as they have to pay attention to syntax rather than developing algorithm (Grover \& Pea, 2013). Thus, scratch programming will be beneficial for the lower secondary students in addressing the problem of syntax. Thus, selecting the correct programming strategy for these students is an essential key factor.

\subsection{Learning Programing through Python}

Python is a programming language that sustains object-oriented approach which is the current trend at tertiary level. It is a language that is compatible with all operating systems. It makes use of punctuation characters as compared to block of codes in Scratch. The use of whitespace allows learners to write codes and it allow them to structure the program in various ways. It also consists of a number of freely available libraries which might help learners in the coding process.

Python programming has been initiated to grade 9 students as from 2020 and the question that is being raised by educators "Does the initiation of python as a programming language suitable for lower secondary level students?"

Most educators pointed that programming syntax is a major pitfall in the teaching and learning programing due to the long statements. Abstraction, clarity of language and irrational structures of python are the other drawbacks. From the learner's point of view, debugging is a problem when codes do not compile and learner's have to remember codes. The following example shows the codes in python for checking password.

\# password checking program

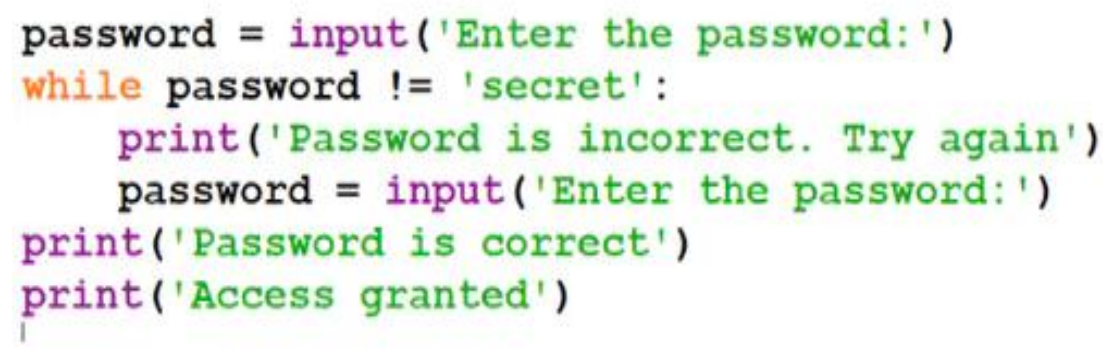

Figure-4.

Python code for checking password.

The student will enter the password. If the password is "secret" then access is granted. If the student has wrongly entered the password, a message "Password is incorrect. Try again" will be displayed to allow the student to re-enter the correct password Figure 4.

\section{Research Design}

The purpose of this study is to assess the difficulties in teaching and learning program through scratch and any programming language (example, Python). Random sampling was considered for the target students of grade 7 to 9. In Mauritius ICT is a core component that is to be assessed at the end of the NCE program and programming forms part of the 9 contents areas that are to be assessed. Grade 9 
students were the target sample for this study. As programming is interrelated problem solving and students had experience scratch during grade 7 and 8, a pre-test was considered in assessing the students. They were exposed to python programming as from grade 9 . The Table 3 below demonstrates how the students had to undergo the programming experiments.

Table-3.

Research Design.

\begin{tabular}{|c|c|c|c|}
\hline \multicolumn{4}{|c|}{ Experiment } \\
\hline & Topic & New terms and instructions & New concepts \\
\hline \multicolumn{4}{|c|}{ Pre-test } \\
\hline \multirow{4}{*}{ Python } & $\begin{array}{l}\text { Algorithms: } \\
\text { sequencing, } \\
\text { conditional and } \\
\text { iteration }\end{array}$ & $\begin{array}{l}\text { Algorithm, sequencing, } \\
\text { conditional } \\
\text { and iteration }\end{array}$ & $\begin{array}{l}\text { Introducing algorithm term, basic } \\
\text { algorithms: sequencing, } \\
\text { conditional and iteration with } \\
\text { examples from real life. } \\
\text { Introducing to Python } \\
\text { programming language }\end{array}$ \\
\hline & $\begin{array}{l}\text { Variable, input and } \\
\text { output }\end{array}$ & Variable, input, print, int & $\begin{array}{l}\text { Basic Python instructions, variable } \\
\text { term and integers with examples } \\
\text { in Python }\end{array}$ \\
\hline & $\begin{array}{l}\text { Input processing, } \\
\text { output process phases } \\
\text { of the computer } \\
\text { program }\end{array}$ & $\begin{array}{l}\text { Arithmetic operations }(+,- \text {, } \\
*, /)\end{array}$ & $\begin{array}{l}\text { Solving simple problems in } \\
\text { Python program using input, } \\
\text { processing including basic } \\
\text { arithmetic operations and output }\end{array}$ \\
\hline & Conditional & If else & $\begin{array}{l}\text { Solving simple problems including } \\
\text { branching algorithm in Python } \\
\text { using if else. }\end{array}$ \\
\hline \multicolumn{4}{|c|}{ Python test, questionnaire about programming and python } \\
\hline \multirow{3}{*}{ Scratch } & $\begin{array}{l}\text { Aquarium simulation } \\
\text { program }\end{array}$ & forward, left, right, repeat & Sprites, concurrency, loops \\
\hline & Chasing ghosts game & If, variables & Conditionals \\
\hline & Simple ricochet game & $\begin{array}{l}\text { communication by messaging, } \\
\text { conditional loops, Coordination } \\
\text { and Synchronisation }\end{array}$ & Loops with conditionals \\
\hline
\end{tabular}

The students were first exposed to Python programming for four weeks. The lectures included selected programming concepts: variables, input, print, sequencing and conditionals. Student skills in Python programming were tested afterwards. Three weeks later, we introduced students to programming in Scratch. We have selected a game-based approach and students were required to program simple games. They were introduced to basic programming concepts like sequencing, conditional and iteration.

The sample population for this study consisted of fifty students (thirty-four boys and sixteen girls) of grade 9 from two schools (one state and one private) in Zone 2.

\section{Assessment Instruments}

Data for this study was collected in 3 stages. First, students were evaluated on their problemsolving skills before initiating programming, then after undergoing through scratch programming and finally after introducing the key concepts in terms of flowchart, python commands such as input and print, variable, and programming construct. At the end, the students had to evaluate their views towards learning programming. 


\section{Analysis of Discussion}

Both qualitative and quantitative methods were chosen for analysis and triangulation approach was adopted to increase the validity of the study (Cohen, Manion, \& Morrison, 2013). T-test was used for comparing results among the different groups while signed rank test was adopted for comparing different students results.

\section{Discussion and Findings}

A problem-solving test was carried out with the 50 students before any programming lectures were held and the maximum marks was 15. Based on the achieved score, students were placed in one of three group; stronger, intermediate and weaker as shown below. Table 4 shows distribution of participants by strength groups. A mean of 11.93 demonstrate that students having problem solving skills were able to recall the information from memory that were needed for writing codes and understanding the syntax of the different structures used in the program as compared to a mean 4.05 for the weaker groups who had some problem solving skills.

Table-4.

Group distribution by students' strength.

\begin{tabular}{c|c|c|c|c}
\hline Group & Number of students & Marks & Mean & Standard Deviation \\
\hline Stronger & 15 & $>=11$ & 11.93 & 1.223 \\
\hline Intermediate & 16 & Between 7 and 11 & 9.69 & 0.704 \\
\hline Weaker & 19 & $<7$ & 4.05 & 2.970 \\
\hline
\end{tabular}

The Figure 5 below shows, students' appreciation towards learning programming through Scratch. 37 of them loved scratch as a visual for learning programming while 13 were not of the same views as they thought that learning programming should be code based in terms of variable declaration as python. 40 students believed that learning Scratch has helped them learn programming due to its block of codes and visual layout.

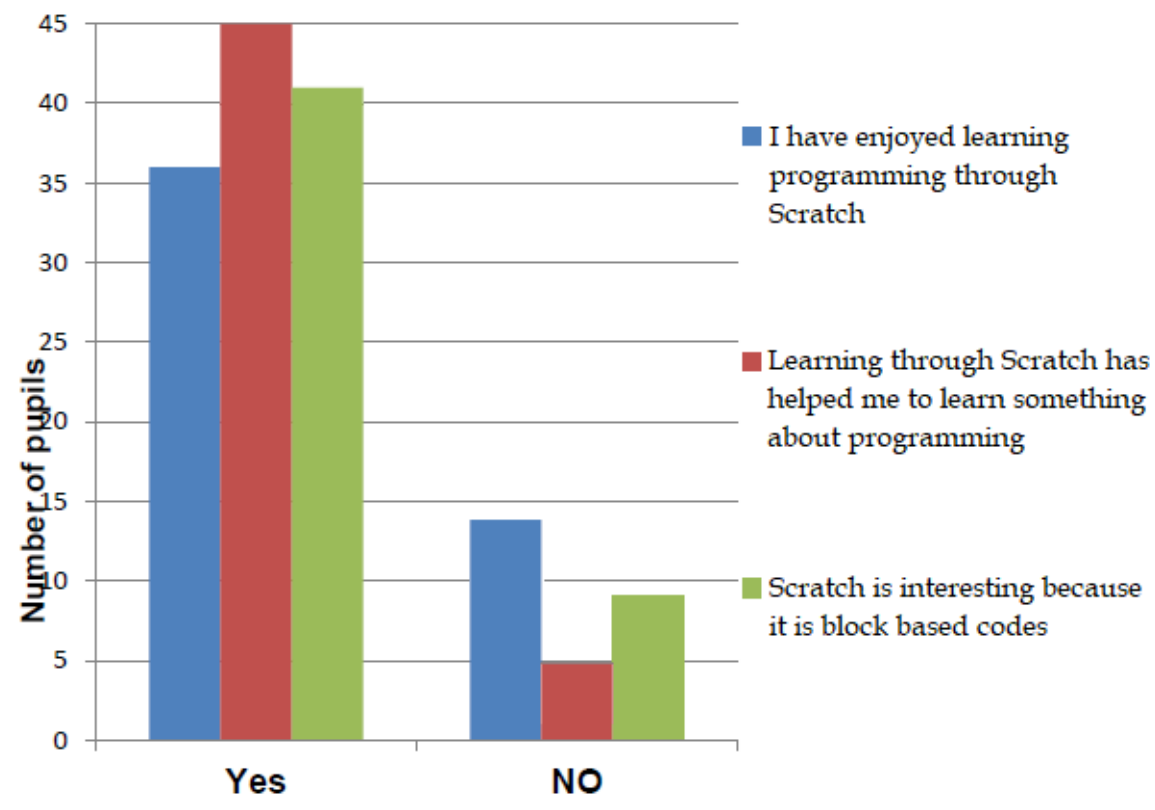

Figure-5.

Trail result on students. 
Two assessments were carried out to evaluate the students' performance in programming. The first assessment was administered following the delivery of Python lectures, while the other one was based on Scratch Programming. Since the number of points in each test was different, we decided to use the percentage as a measure of success. The Kolmogorov-Smirnov (S-test) test showed that there is a normal distribution of data in both Python $(\mathrm{p}=0.198)$ and Scratch $(\mathrm{p}=0.068)$ tests. The Table 5 below shows descriptive statistics results.

Table-5.

Descriptive results of student's performance.

\begin{tabular}{l|c|c|c|c}
\hline \multirow{2}{*}{ Stronger } & \multicolumn{2}{|c|}{ Python } & \multicolumn{2}{c}{ Scratch } \\
\cline { 2 - 5 } & Mean & $\begin{array}{c}\text { Standard } \\
\text { Deviation }\end{array}$ & Mean & $\begin{array}{c}\text { Standard } \\
\text { Deviation }\end{array}$ \\
\hline Intermediate & 81.667 & 20.5116 & 76.953 & 19.7003 \\
\hline Weaker & 61.831 & 22.5395 & 71.575 & 19.0275 \\
\hline
\end{tabular}

As the Python results did not meet the hypothesis of the normal distribution, a Kruskal-Wallis test was carried out which demonstrated substantial difference among the different groups $\left(\chi^{2}(2)=19.343\right.$, $\mathrm{p}=0.000)$. The above table shows that the brighter students performed better as compared to the two other groups. So, ANOVA test was carried to compare the group results of the Scratch test and it was concluded that there exist substantial differences among the groups. This can be established by a single ANOVA $(\mathrm{F}(2,47)=6.945, \mathrm{p}=0.003)$. As a substantial difference exists among the groups, we had to perform a further analysis and a Mann-Whitney U test was employed.

For this analysis we had to consider only the intermediate and stronger students and the statistic was computed to define whether any difference exists between them and the result were as follows $(\mathrm{U}$ $=63,5, \mathrm{z}=-2,277, \mathrm{p}=0,023)$. It can be concluded the stronger group performance was better than the intermediate one. But no significant difference was noticed in Scratch programming between the two groups ( $\mathrm{U}=99,6, \mathrm{z}=-0,838, \mathrm{p}=0,419)$. So, we could conclude that Scratch programming was better to motivate intermediate and lower problem-solving skills students in learning programming as the result correlate with other researches where students programming skills were boost up through learning animations.

Next, we had to use a t-test in order to make a comparison between intermediate and weaker one. The results demonstrated that the brighter group performed better than the weaker ones in Python $(\mathrm{t}$ $(33)=3,141, \mathrm{p}=0,006)$, and Scratch $(\mathrm{t}(33)=2.789, \mathrm{p}=0.010)$. it can be concluded that the weaker group had difficulties in understanding programming regardless of the software being used. Eventually, based on the result, we had to accept $\mathrm{H}_{1}$ as problem solving skills are directly interrelated to the success in Python. But this in not the case in Scratch as both the brighter and the intermediate students were successful in accomplishing their tasks and so we could reject the H2. We can conclude that students with higher problem-solving skills can master programming regardless the programming software. Another finding is that visual programming through scratch helped to boost up students' motivational level in learning problem solving. Thus, it is worth for Grade 9 students to be exposed to new programming languages in order to discourage students from quitting programming.

The $\mathrm{H} 3$ is expected to give positive outlook towards learning programming after mastering Scratch as compared to Python. After conducting some lessons about programming in Python, students answered a Likert scale question of five items about their attitude towards programming. This question was repeated in the small questionnaire students answered after the Scratch lessons. The questionnaire was composed of four Likert scale questions regarding their attitude towards the programming languages used.

The Table 6 illustrates the questions. 
Table-6.

Questions related to survey.

\begin{tabular}{c|c|l}
\hline & \multicolumn{2}{|c}{ Questions } \\
\hline After Python & $\mathrm{Q}^{1}$ & How much do you like programming? \\
\hline \multirow{4}{*}{ After Scratch } & $\mathrm{Q}^{2}$ & How much do you like programming? \\
\cline { 2 - 3 } & $\mathrm{Q}^{3}$ & How much do you like Python? \\
\cline { 2 - 3 } & $\mathrm{Q}^{4}$ & How much do you like Scratch? \\
\cline { 2 - 3 } & $\mathrm{Q}^{5}$ & Which programming language do you prefer? \\
\hline
\end{tabular}

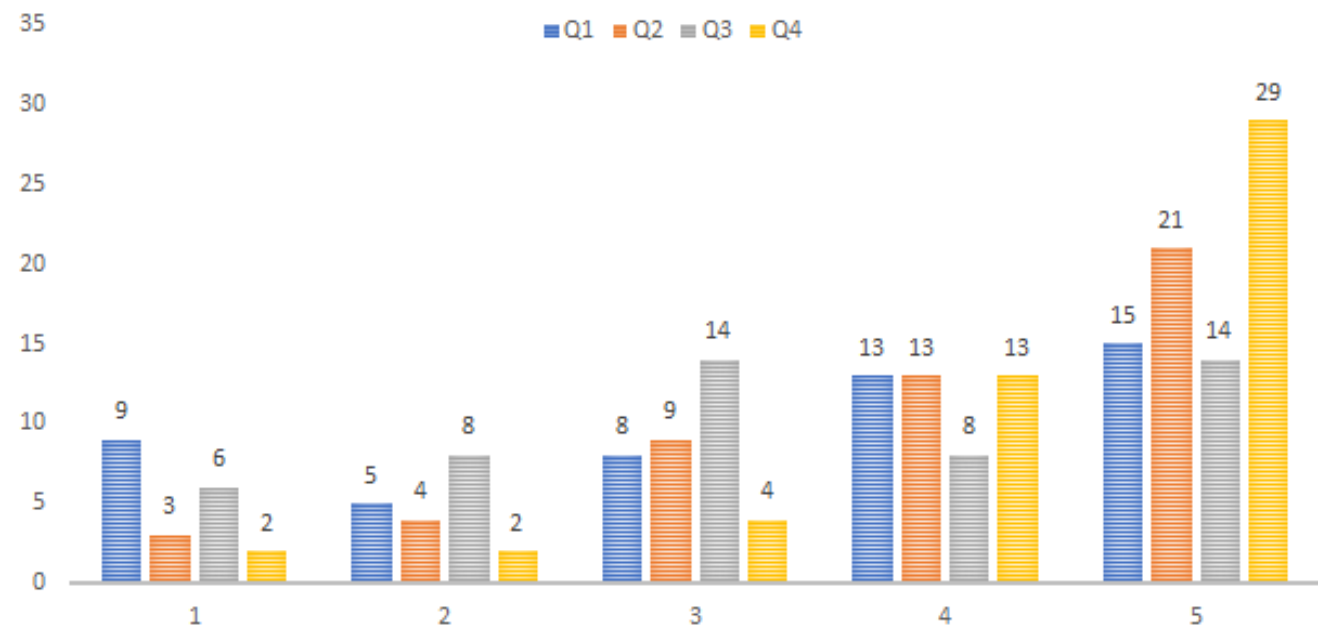

Figure-6.

Frequencies of results.

The above Table 6 demonstrates the frequency distribution (numbers at the top of the bar) of the different questions regarding learners 'attitude towards the programming languages used. It is clear that 29 students prefer Scratch as compared as a programming language and that they showed a positive attitude towards programming.

From the findings it is clear that $76 \%$ of the respondents prefer to use Scratch as a programming language as compare to $24 \%$ who opted for Python.

The Figure 7 shows the results of Q5.

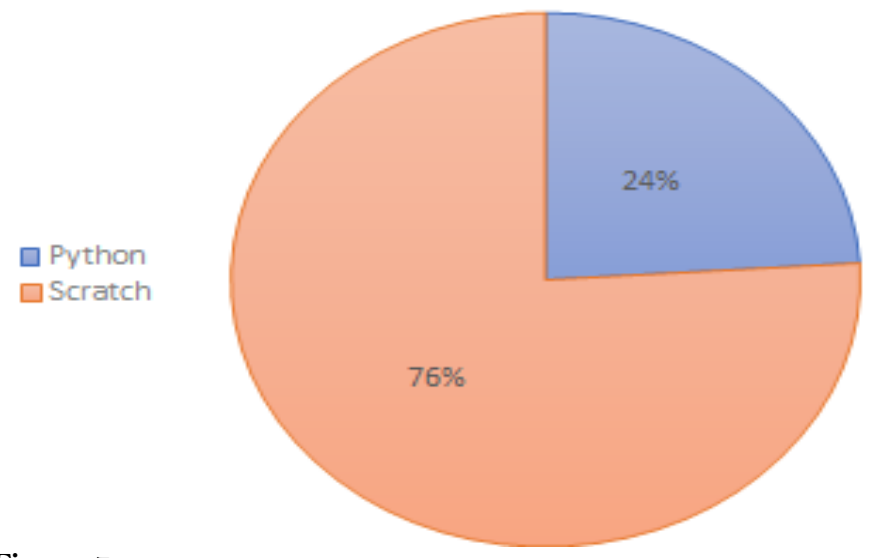

Figure-7.

Result for Q5. 
We compared the attitude of students towards programming and the difference between $\mathrm{Q} 1$ and Q3 are tabulated below.

Table-7.

Student preference of programming languages.

\begin{tabular}{c|c|c|c|c}
\hline Dependent variable & $\begin{array}{c}\text { Learning method } \\
\text { (Independent Variable) }\end{array}$ & Percentage & Mean & $\begin{array}{l}\text { Standard } \\
\text { Deviation }\end{array}$ \\
\hline $\begin{array}{c}\text { Student attitude towards } \\
\text { programming }\end{array}$ & Sractch & 76 & 3.35 & 1.057 \\
\cline { 2 - 5 } & Python & 24 & 0.57 & 0.59 \\
\hline
\end{tabular}

The Table 7 shows the mean of the variable "Student attitude towards programming" for the two different programming languages and this statistical data is compared in Table 8. From the table 7, it is clear that learners had a greater affiliation for programming after Scratch (76\%) compared to Python (24\%). This confirms that Scratch had a positive effect, with a mean of 3.35 on student attitude towards programming as compared to 0.57 to Python. Thus, we can accept $\mathrm{H} 3$ and conclude that attitude towards programming is more positive after Scratch than after Python. However, it came as a surprise that even after being introduced to Scratch, a handful of students still preferred Python due to their problem-solving skills. We assumed that these are the students are the intelligent ones and are devoted to problem solving skills.

An independent sample was used here as a method to statistically compare the means of "Which programming language to learner prefer?". By looking at the statistical data in Table 8 , it can be noticed there is a statistically significant difference in the attitude towards programming language; as shown in the Sig. (2-tailed) column, the significance result is 0.00, which is less than 0.05 (the result of the level of significance or $\mathrm{P}$ value).

Table-8.

Scratch programming preferences.

\begin{tabular}{l|c|c|c|c|c|c|c|c|c}
\hline $\begin{array}{l}\text { Dependent } \\
\text { Variable }\end{array}$ & \multicolumn{2}{|c|}{$\begin{array}{l}\text { Levene's test } \\
\text { for equality } \\
\text { of variances }\end{array}$} & \multicolumn{6}{|c|}{ T-test for Equality of Means } & \multicolumn{2}{|c|}{$\begin{array}{l}\text { 95\% confidence } \\
\text { interval of the } \\
\text { differences }\end{array}$} \\
\hline $\begin{array}{l}\text { Which } \\
\text { programming } \\
\text { language do } \\
\text { you prefer? }\end{array}$ & $\mathrm{F}$ & $\mathrm{Sig}$ & $\mathrm{T}$ & $\mathrm{df}$ & $\begin{array}{l}\text { Sig (2- } \\
\text { tailed) }\end{array}$ & $\begin{array}{c}\text { Mean } \\
\text { difference }\end{array}$ & $\begin{array}{l}\text { Std Error } \\
\text { Difference }\end{array}$ & Lower & Upper \\
\hline $\begin{array}{l}\text { Equal variance } \\
\text { assumed }\end{array}$ & 0.17 & 0.69 & 2.21 & 43 & 0.03 & -0.742 & 0.334 & -1.421 & -0.063 \\
\hline $\begin{array}{l}\text { Equal variance } \\
\text { not assumed }\end{array}$ & & & 2.22 & 42.80 & 0.03 & -0.742 & 0.334 & -1.422 & -0.062 \\
\hline
\end{tabular}

The Table 9 below shows the mean of the variable "I have enjoyed learning programming" and its statistical result. It is clear that more learners preferred Scratch as it has a better (0.982) standard deviation as compared to Python.

Table-9.

Enjoy learning programming.

\begin{tabular}{c|c|c|c} 
Enjoy learning programming. & \multicolumn{2}{|c|}{$\begin{array}{c}\text { Learning method } \\
\text { Dependent variable }\end{array}$} & $\begin{array}{l}\text { Standard } \\
\text { Deviation }\end{array}$ \\
\hline $\begin{array}{c}\text { I enjoyed learning } \\
\text { programming }\end{array}$ & Scratch & 1.65 & 0.982 \\
\cline { 2 - 4 } & Python & 2.56 & 0.324 \\
\hline
\end{tabular}


An independent sample was used here as a method to statistically compare the means of enjoyment for both programming languages. By looking at the statistical data in Table 6.10, it can be noticed there is a statistically significant difference in the enjoyment; as shown in the Sig. (2-tailed) column, the significance result is .000, which is less than 0.05 (the result of the level of significance or P value).

Table-10.

T-test about I have enjoyed learning programming.

\begin{tabular}{l|c|c|c|c|c|c|c|c|c}
\hline $\begin{array}{l}\text { Dependent } \\
\text { Variable }\end{array}$ & \multicolumn{2}{|c|}{$\begin{array}{l}\text { Levene's test } \\
\text { for equality } \\
\text { of variances }\end{array}$} & \multicolumn{6}{|c|}{ T-test for Equality of Means } & \multicolumn{2}{|c|}{$\begin{array}{c}\text { 95\% confidence } \\
\text { interval of the } \\
\text { differences }\end{array}$} \\
\hline $\begin{array}{l}\text { I have enjoyed } \\
\text { learning } \\
\text { programming. }\end{array}$ & $\mathrm{F}$ & $\mathrm{Sig}$ & $\mathrm{T}$ & $\mathrm{df}$ & $\begin{array}{c}\text { Sig (2- } \\
\text { tailed) }\end{array}$ & $\begin{array}{c}\text { Mean } \\
\text { difference }\end{array}$ & $\begin{array}{c}\text { Std Error } \\
\text { Difference }\end{array}$ & $\begin{array}{c}\text { Lower } \\
\text { Upper }\end{array}$ \\
\hline $\begin{array}{l}\text { Equal variance } \\
\text { assumed }\end{array}$ & 10.48 & 0.003 & -4.57 & 49 & 0.000 & -1.32 & 0.289 & -1.89 & -0.73 \\
\hline $\begin{array}{l}\text { Equal variance } \\
\text { not assumed }\end{array}$ & & & -4.49 & 43.9 & 0.000 & -1.32 & 0.293 & -1.92 & -0.72 \\
\hline
\end{tabular}

This statistical technique was used for comparing the mean scores on student's enjoyment in learning programming. For the $t$-test, the mean is -1.32 with a standard deviation error greater than 0.2. With $95 \%$ confidence, the difference in mean between lower and upper interval is less than 0 and the results shown that pupils who learnt programming traditionally found programming a boring and difficult process, and this had severely affected their motivation and acceptance of programming in the school.

\section{Conclusion}

A moderate introduction to programming is required at secondary level for Grade 7 students, where students should focus on problem solving and algorithms through the introduction of visual programming. So scratch programming provides syntax free blocks of codes that motivate students to learn programming. This helps educators to shift their teaching strategies from solving mathematical problems to game programming which boost up students' attitudes towards programming. Scratch programming is an effective tool to transfer visual into real programming language like Python. Students with high problem-solving skills can master programming irrespective of the programming language and those with lower problem-solving skills encounter different problems in mastering the programming concepts.

The lack of research in this area was a disadvantage as results could not be compared. As the study was carried out with 50 students only, the result did not show the reality and only one zone was considered. The result also pointed that there is no difference between intermediate students and brighter students in learning programming through scratch. The majority of the students preferred scratch and learning python first seems to be a problem for initiating programming. We believed that students' motivation to programming would be lower if syntax was to be introduced first.

\section{References}

Armoni, M., Meerbaum-Salant, O., \& Ben-Ari, M. (2015). From scratch to "real" programming. ACM Transactions on Computing Education, 14(4), 1-25. Available at: https://doi.org/10.1145/2677087.

Cohen, L., Manion, L., \& Morrison, K. (2013). Research methods in education. Forehand, M. “Bloom's Taxonomy," Emerging perspectives on learning, teaching, and technology: Routledge.

Forehand, M. (2010). Bloom's taxonomy. Emerging Perspectives on Learning, Teaching, and Technology, 41(4), 47-56.

Govender, I. (2006). Learning to program, learning to teach programming: Pre- and In-service teachers' experiences of an object-oriented language. Unpublished Doctoral Dissertation, University of South Africa. 
Grover, S., \& Pea, R. (2013). Computational thinking in K-12: A review of the state of the field. Educational Researcher, 42(1), 38-43. Available at: https://doi.org/10.3102/0013189X12463051.

Hromkovi`c, J. (2006). Contributing to general education by teaching informatics. In R. Mittermeir (Ed.), Informatics education \{the bridge between using and understanding computers (Vol. 4226). Berlin / Heidelberg: Springer.

Koehler, M., \& Mishra, P. (2009). What is technological pedagogical content knowledge (TPACK)? Contemporary Issues in Technology and Teacher Education, 9(1), 60-70.

Krathwohl, D. R. (2012). A revision of Bloom's taxonomy: An overview. Theory into Practice, 41(4), 212-218. Available at: https://doi.org/10.1207/s15430421tip4104_2.

Mawby, R., Kurland, D. M., Pea, R. D., \& Clement, C. (2009). A study of the development of programming ability and thinking skills in high school students.

Ministry of Education Arts and Culture. (1991). Master plan for the year 2000. 125-180.

Papert, S. (2006). Programming versus application. In R.T. Mittermeir (Ed.), Issep 2006, Incs 4226. Berlin/ Heidelberg: Springer.

Rayner, S. G. (2015). Cognitive styles and learning styles. In, J.D Wright, (Ed.), International Encyclopedia of Social and Behavioral Sciences (2nd ed., Vol. 4, pp. 110-117). Oxford: Elsevier.

Resnick, M., Maloney, J., Monroy-Hernández, A., Rusk, N., Eastmond, E., Brennan, K., \& Silverman, B. (2009). Scratch: Programming for all. Communications of the ACM, 52(11), 60-67.

Rutherfoord, H., \& Rutherfoord, J. (2008). Exploring teaching methods for on-line course delivery-using universal instructional design. Paper presented at the Proceedings of the 9th ACM SIGITE Conference on Information Technology Education. ACM, 16th October 2008.

Shulman, L. (2006). Those who understand: Knowledge growth in teaching. Educational Researcher, 15, 4-14.

Soloway, E., \& Spohrer, J. (2009). Studying the novice programmer (pp. 497). Hillsdale, New Jersey: Lawrence Erlbaum Associates.

Stephenson, C., Gal-Ezer, J., Haberman, B., \& Verno, A. (2015). The new educational imperative: Improving high school computer science education (Tech. Rep.). Final Report of the CSTA Curriculum Improvement Task Force - February 2015.

Stickel, M. (2009). Impact of lecturing with the tablet PC on students of different learning styles. Paper presented at the Frontiers in Education Conference, FIE'09.39th, IEEE 18th October 2009.

Survey of ICT and Education in Africa: Mauritius Country Report. (2007). InfoDev ICT and education series. Washington, DC: World Bank.

Thompson, E. (2008). Bloom's taxonomy for CS assessment. Paper presented at the Proceedings of the Tenth Conference on Australian Computing Education, Australian Computer Society, Inc.

Wikipedia. (2020). Computer Programming.Wikipedia, Wikimedia Foundation, 29 July 2020, en.wikipedia.org/wiki/Computer Programming.

Journal of Contemporary Research in Social Sciences
ISSN : 2641-0249
Vol. 3, No. 3, pp. $48-61,2021$
DOI: $10.33094 / 26410249.2021 .33 .48 .61$
C) 2021 by the authors; licensee Learning Gate

